\title{
Foresight Education: Semantic and Value Priorities of Educational Landscape
}

\author{
Tatiana Leshkevich \\ Southern Federal University \\ Rostov-on-Don, Russia \\ E-mail: Leshkevicht@mail.ru
}

\begin{abstract}
The article considers the key characteristics of future education, defined by the digital era. The author reviews the prospects for education and justifies the need for a new type of subjectivity corresponding to the requirements of the sixth technological wave. The main aim is to identify characteristics and values of foresight education. The article dwells on four aspects of the issue. Firstly, the author analyses the problem of the "rented knowledge", generated by the dominance of digital skills. Secondly, the dilemma of "living" education vs. "digital" education is considered with due regard to a "new social network". Thirdly, value priorities of modern educational strategies are revealed. Fourthly, the author justifies the importance of wisdom as the fundamental principle of transformations in education. The methodological base of the study involves the dialectic method, the categories of content and form, the principle of realism and the systemic approach. The article claims that there exists an intermediate educational model - "rented knowledge", with digital skills being its resource. The modern education strategy is based on a mixture of traditional educational practices and mass online education. The strategy of future education involves adopting a new type of subjectivity within which humanitarian priorities of education are complemented by digital skills. The formation of genuinely human value orientations is connected with the concept of wisdom indicating a state when theoretical awareness and moral maturity are translated into practical application. The higher the potential of wisdom, the greater its influence on educational landscape with a focus on universal human values.
\end{abstract}

Keywords-foresight education; digital skills; subjectivity; communication practices; wisdom

\section{INTRODUCTION}

Rapid development of the modern world leads to qualitative transformations in education system. Nowadays it is not enough for education system to respond to changes in reality; it should rather stay ahead of them. It is sometimes argued that education is a conservative sphere of society and the educational landscape tends to preserve its configurations resisting changes. A class-lesson system may be a vivid example. Introduced by Y. Komensky in the 17th century it is still considered to be the norm of educational process including universities that generally use the same pattern. Since the middle of the 20th century, scholars have challenged the effectiveness of the traditional education system claiming its archaic nature. Basically, criticism was directed at the rehearsal techniques of studying and teachercentered approach.

Changes in existing technologies have led to a number of radical transformations in the education system. There has been a shift from the hierarchical system of educational process towards the communication principles of distribution networking. It has become clear that both form and content of the future education should meet the requirements of modern civilization.

Analysis and assessment of both positive and negative effects of education system, aimed at technological needs of the future, has formed into a specific research area. Foresight education seems to be an acute problem in the contexts of personal growth, elaboration of specialized technologies as well as for the global development strategy in general.

\section{THE PROBLEM OF ‘RENTED’ KNOWLEDGE}

Some scholars claim that 2020 may be seen as a milestone when the whole human culture will be digitized. The transition to the sixth technological wave shifts the emphasis to a vital role of human competencies. A mere reproduction of existing knowledge and the underlying rehearsal system become critically insufficient, while developing one's cognitive and creative abilities aimed at obtaining something new are of greater relevance. The concept of classical education is also challenged due to the fact that existing knowledge is inexhaustible, on the one hand, and on the other, possessing knowledge is not the basic requirement any more. The focus is shifted to the ability to find relevant data, to the effective and expedient information search. Thus, modern educational paradigm is being shaped around a peculiar "rent" of knowledge gradually replacing a traditional set of requirements: to know, to remember, to think.

"Rented" knowledge seems to be an obvious effect accompanying the transition to a digital era. It is digital skills, which define practical abilities and their situational application, that become critically important in the context of modern existence. They induce changes in all interaction patterns. Within the actual educational space, the leading place does not belong to fast-thinkers (P. Bourdieu) but to those who can find relevant information, use it and get quick access to the Internet. "Rented" knowledge is viewed as one 
of the major issues of modern education. On the one hand, it is clear that in order to maintain advanced technologies we need dynamic and specific training rather than a classical pattern of education that offers an alphabetical set of disciplinary knowledge. But on the other hand, we cannot fail to see that a mere absorption of information is often fragmented and unsystematic in nature, which may lead to losing informational interconnectedness and cause-and-effect relationships. Researchers seem to be concerned about these transformations, assessing them as negative [1]. At the same time, scholars unanimously agree that the image of a Man of the Future is incomplete without basic digital skills that reflect the tendencies of modern development.

When considering the problems of foresight in education, one should also pay attention to some other features that are typical of the current situation. For instance, leaving a "network footprint" has become a significant trend in the modern world. The number of "likes" received in social networks is now seen as the criteria for success. The value of impressions and imitative symbolic capital appear to be stronger than the value of personal knowledge, reflection and the ability to remember and to know. While the distinction between real life and virtual reality is disappearing, "to seem and not to be" is becoming the leading principle of modernity. Some scholars reveal a specific attractive force of computer visualization and address the acute problem of Internet addiction which is viewed as a severe disorder leading to psychological dependency and losing cause-andeffect relationships. It should be emphasized that scientometric citation data can in a way be viewed as similar to such "network success". A scientist's status based on his ratings is also a quantitative rather than qualitative parameter, given that citing indicators can be inflated by means of commercial technologies. Thus, the changes that now occur in educational process make it possible to conclude that the current transition stage is connected with the education model which is based on the resource of "rented" of knowledge. To operate that model successfully one needs to master certain skills such as handling a significant amount of interrelated information and managing network content. Applied practice-oriented skills are of particular importance as they are aimed at putting knowledge into practice. Here, the well-known principle "do no harm" is effective.

\section{III. 'LIVING' EDUCATION VS. 'Digital' EDUCATION}

Today, when the Internet deprives the teacher of the monopoly of knowledge, when network practices and online services tend to "go viral", a dilemma arises: "living" education or "digital" education. It reflects the dispute between the supporters of traditional education practices, on the one hand, and the advocates of mass on-line education, on the other. Analyzing this situation, it is worth mentioning that while the traditional lecture-format is now largely outdated, and modern education does not comply with the value-for-money principle, there arises a question of the value of higher education as such. It seems clear, that rejecting changes in traditional education is the worst option. It is the sixth technological wave that is most likely to transform all the components of educational process substantially. This leads us to a conclusion that a new type of subjectivity is required, whose digital skills can be seen as a prerequisite for success. In the work with a remarkable title "An avalanche is coming. Higher education and the revolution ahead" M. Barber, C. Donnelly, S. Rizvi write: "We need citizens ready to take personal responsibility both for themselves and for the world around them... We need citizens who are ready and able to take their knowledge of the best that has been thought and said and done and apply it to the problems of the present and the future" [2].

At the same time, according to the principle of realism, one should take into account the economic situation of a country, its local specificity. The choice of a particular strategy is mediated by the mechanisms of political institutions. Presumably, the factor of social inertia tends to slow down radical changes. The global world has a significant impact on all types of communication and interactions. We can't fail to agree with scholars who believe that translation of national values and shaping one's civic position will remain a priority in the global world [3]. It may be assumed that even against the background of unification and post-nationality induced by globalization the translation of national values has to remain feasible. National worldviews are permeated with sustainable stereotypes and are aimed at preserving the integrity of national consciousness and authentic cultural traditions. Figuratively speaking, they are "the immune system" of an ethnic group. A person of a particular ethnic background perceives the world through the prism of his own personal orientations and mental attitudes, which are not likely to be completely destroyed by the "waves of globalism". However, they are predominantly translated through "live" communication. At the same time, the truth is that future generation has to be well prepared to enter into adulthood in the 21 st century. Otherwise they have no future, or at least might find themselves unable to take an active part in shaping the future.

But how is it possible to overcome the dilemma of "live" education vs "digital" education in the context of ongoing transformations? In our opinion, the analysis of the existing circumstances enables us to come to the following conclusions. Firstly, "new sociality of the network" should be recognized as the platform for the modern educational landscape. Secondly, it would be reasonable to implement "mixed" educational patterns, including traditional live classes, online courses and innovative game-based techniques. Thirdly, it may be essential to provide individualized learning paths if a person is capable of formulating his own goals and objectives and designing his own life path. Fourthly, the idea of mentoring remains extremely relevant in the context of Foresight education. In the fifth place, it should be noted that open on-line lectures by established scholars is a valuable resource of innovative education strategies, which is available to the general public. The opportunity to listen to online lectures in any part of the world is the evidence of the growing global sector in education.

It has become clear that globalization brings about new requirements for future specialists. These requirements include cultural awareness and multicultural communication 
skills since human interactions in the modern world go beyond national and geographical boundaries. In this regard, communicative practices aimed at successful interactions might be of particular importance. They often serve as regulators of life search, revealing the motivation of dialogue parties. In addition to adjusting personal goals, communicative practices "expertise" the existing situation. They are connected with psycho-mental attitudes of communicating subjects, their preferences and choices, and contribute to shaping both public and individual expectations [4]. In our view, communication practices can be seen as a linking element between "living" education and "online" education. They demonstrate the value of both independent decisions and collaborative solutions. Thus, communicative practices combine flexibility and independence of thought, on the one hand, and a system approach and broader vision of an overall picture, on the other.

\section{EDUCATION PRIORITIES AND THE PROBLEM OF WISDOM}

In the current context, when natural and exact sciences are based on probability models, a universal algorithm of educational process is hardly possible at all. We would like to note here that within a standard education system a teacher used to be a key figure having an expertise in his disciplinary area and the only source of knowledge. It was the teacher who acquainted the novice with the basics and specifics of his discipline. Each of the students had to master this basic thesaurus and become a member of disciplinary cohort, thus contributing to disciplinary continuity.

According to some scholars, all processes and mechanisms revolved around the disciplinary cohort.

Even if justifications of new elements of science were published in scientific journals, they were in-built in the corpus of obligatory knowledge some time later and with considerable loss, in spite of the fact that "according to calculations, the number of the elements of scientific knowledge tends to double every10 years [5].

Thus, for many centuries a teacher-to-student way of transferring disciplinary knowledge was considered to be the basic mechanism of traditional education system. The assistance in learning a complicated subject provided by the teacher was one of the value priorities of teaching. It was based on both teacher skills and personal teacher-student interaction. It was the experience of personal contact that was seen as an important semantic priority of instruction and education. Moreover, personal interaction led to further professional connections and relationships. The notion of professional cohort helped to understand the process of career making, promoting ideas and reward system. The professional cohort acted as a moderator assessing the intellectual capital and young scientist's abilities. This guaranteed a certain level of acceptance in scientific community.

While the duration of being a member of a disciplinary cohort used to be of great importance, now the situation has changed. Rapid technological development has resulted in shifting the focus to mastering digital skills in order to use modern technologies. There has emerged a new priority based on modern specialists' instrumental digital skills. While the question of their socio-humanitarian background has been downgraded on the list of priorities. At the same time, we assume that radical transformations in education should not undermine universal human values: morality, justice, science ethics and responsibility. But since humanitarian education has been sidelined, and social entropy is increasing, criteria for foresight education have to be defined. What kind of person are we expecting to see in the future? The demand for applied knowledge and practical skills needed to use modern technologies poses an acute problem of whether an individual working in the sphere of maintenance of technologies will have the right to bear a proud name of Man. Or will he be a "partial person" in Karl Marx's concept? What is viewed as an ultimate priority: benefit, profit, technological innovations or human personality with its aspiration to development and selffulfillment?

We believe that, high standards of morality and genuine humane values should be translated into the future as the main value. We believe that wisdom is the basic education principle and the main priority for a man of the future. Wisdom indicates the state when theoretical knowledge and moral maturity are translated into practical application. Incorporating knowledge, experience and morality, wisdom appears to be a guide to a quality choice of behavior patterns. Wisdom manifests itself in the way of life. Therefore, raised to the rank of fundamental humanitarian criterion, wisdom will contribute to shaping educational landscape with due regard to universal human values. Ancient philosopher Democritus argued that three abilities stem from wisdom: to deliberate well, to speak to the point, to do what is right [6]. According to René Descartes, wisdom is interpreted as both prudence and knowledge that defines life practices, contributes to health preservation, and facilitates scientific progress. Wisdom is the highest good of human life [7]. Wisdom provides guidance for the formation of moral subjectness, contributes to balancing complex human-world interactions and indicates the need for environmentally responsible behavior. The prospect can be seen in the transition to environmental friendliness of one's own acts and environmental awareness. And the higher the potential of wisdom, the greater it influences social life and existence as such. Wisdom is a universal value that is effective both on a global scale and in everyday life. Thus, we might assume that wisdom sets a different frame of reference within which genuinely humane value orientations are the most significant ones.

\section{CONCLUSION}

The foresight analysis of education in the context of digital era leads us to the following conclusions. Firstly, nowadays we can witness the formation of a new type of sociality - a "network sociality", which creates the demand for digital skills, "rented knowledge", "mixed" education practices and individualized learning paths. Secondly, this implies new demands on both a teacher and a future specialist. The idea of mentoring and personal teacher- 
student contact, as well as open online lectures addressed to the mass audience, remain important. "First-hand knowledge" and expertise are seen as a priority of Foresight Education.

In our view, a sufficient set of competencies for the future specialist might include:

- The ability to operate a vast amount of interrelated information;

- Cultural awareness;

- Mastering the language of cross-disciplinary communication;

- Enhancing personal responsibility and adhering to the principles of science ethics.

It stands to reason that radical changes in education technologies shouldn't undermine valuable priorities of human existence. The analysis shows that it is impossible to narrow education down to practical training alone, nor is it possible to limit professional skills to the maintenance of technologies. While entrepreneurial skills appear to be useful in applied research, independent expertise, aimed at revealing negative consequences of technological development, requires a different kind of knowledge. Both the principle of objectivity and an unbiased view of an independent professional are in demand in this case. Therefore, foresight education enables us to articulate our vision of a Man of the Future. It seems that the solution to this problem should be based on the resource of wisdom, which combines knowledge, morality and practical action. At the same time, creative and ethical thinking, the ability to generate and justify ideas remain among the priorities of foresight education. Thus, it is not just "knowledge for the sake of knowledge" that is important; nor it is practicality alone. The whole paradigm should be centered on a person striving for truth, goodness and beauty.

\section{REFERENCES}

[1] T. Leshkevich, Philosophical meaning of modern transformations of education //Proceedings of the 3rd International Conference on Arts, Design and Contemporary Education (ICADCE 2017). Advances in Social Science, Education and Humanities Research, volume 144, pp. 650-653.

[2] M. Barber, K. Donnelly, S. Rizvi, An avalanche is coming. Higher education and the revolution ahead http://med.stanford.edu/smili/support/FINAL\%20Avalanche\%20Pape r\%20110313\%20(2), p. 3.

[3] O.V. Chistyakova, Self and other in the communicative space of the global world" in Proceedings of the 2017 2rd International Conference on Contemporary Education, Social Sciences and Humanities Research, Paris: Atlantis Press, 2017, pp. 6-11

[4] T. Leshkevich, Communicative Practices in Their Semantic Orientation on Algorithms of Successful Interactions//Proceedings of 4th International Conference on Education, Language, Art and Intercultural Communication (ICELAIC 2017). M.: 2017. Vol. 142, pp. 374-377.

[5] M.K Petrov, The History of the Institutions of Science. The Experience of the Institutional History of Science on the Material of the Anglo-American Scientific Tradition. Rostov-on-Don, SFU, 2017, p. 56.
[6] Sylvia Berryman https://plato.stanford.edu/entries/democritus/

[7] R. Descartes, Selected works. M.-L.: State Publishing House, 1950, p. 411 